\title{
Universal Design for Learning to Support Access to the General Education Curriculum for Students with Intellectual Disabilities
}

\author{
Adnan Nasser Al Hazmi ${ }^{1, *}$ \& Aznan Che Ahmad ${ }^{1}$ \\ ${ }^{1}$ School of Educational Studies, University Sains Malaysia, 11800 Gelugor, Pulau Penang, Malaysia \\ *Correspondence: School of Educational Studies, University Sains Malaysia, 11800 Gelugor, Pulau Penang, \\ Malaysia. E-mail: alhazmi_uk@hotmail.com
}

Received: February 14, 2018

Accepted: March 26, 2018 Online Published: April 3, 2018

doi:10.5430/wje.v8n2p66

URL: https://doi.org/10.5430/wje.v8n2p66

\begin{abstract}
The issue concerned with enhancing support to the intellectually disabled students for enabling them to access the general education has gained significant importance in the recent years all over the world. The intellectually disabled students suffer from neurodevelopmental disorders that acts as a barrier to the normal functioning of the brain and slow down the learning abilities and proper development of an individual. The presence of intellectual disabilities affects both the mental and physical well-being of the students by causing issues for them to understand, think logically, speak, remembering things, and find solutions to the problems. Many research studies are conducted across the world for finding the ways and designing innovative models that can help in increasing the access to general education for these students with special needs. The universal design for learning framework also aims at providing support to the intellectually disabled students for gaining access to general education by enhancing their intellectual functioning and ability to adapt.
\end{abstract}

Keywords: universal design for learning, intellectual disabilities, general education curriculum

\section{Introduction}

The framework of Universal design for learning (UDL) is introduced and applied with the aim to improve access to general education among children and to foster students' participation and support their learning needs. UDL framework is centred on enhancing students' access to general education curriculum via minimising barriers to instruction (Wehmeyer et al., 2003; Wehmeyer, 2006). It is evident that students possess different abilities and their educational needs and preferences vary; wherein it is noted that a large heterogeneous group is encountering challenges in learning and fulfilling their educational requirements due to several reasons (Wehmeyer et al., 2003; Wehmeyer, 2006). Students belonging to the heterogeneous group of sensory disabilities, behavioural challenges, learning disabilities, autism spectrum disorders and attention deficit disorder face issues in accessing general education curriculum due to the absence of flexible learning and teaching practices (Edyburn, 2010; Shurr \& Bouck, 2013). In this context, UDL intends to fill the gap residing concerning learning environment in regard to the access of general education to students having different learning needs by the inclusion of flexibility in learning (Edyburn, 2010; Räty, Kontu \& Pirttimaa, 2016).

The Individuals with Disabilities Education Act (IDEA) enacted for meeting requirements of access to general education to disabled students; wherein emphasis has been given to the formulation of Individualised Education Programs (IEPs) for supporting educational progress of children with disabilities (Coyne et al., 2012). The designing of curriculum integrated three key principles of presenting information through flexible and numerous methods so that students can obtain adequate knowledge. It also comprises of flexible and multiple means of expression so that children can showcase their learnings along with the inclusion of various alternatives for increasing student engagement and for maintaining motivation among them (Coyne et al., 2012; Wehmeyer, 2006). In this context, the paper aims to examine the role of universal design for learning in supporting access to the general education curriculum for students with intellectual disabilities. In order to fulfil the aim, current practices followed universally in imparting education to intellectually disabled students are discussed and reviewed in detail. Additionally, theories supporting access to general education amidst students with intellectual disabilities and issues faced by intellectually disabled students in accessing general education for improving understanding of the need of employing UDL. 
Further, ways to integrate new universal designs for learning are also included in the paper. The paper concludes the practices concerning implications of UDL to support access to general education among children with intellectual disabilities.

\section{Intellectual Disabilities}

Intellectual disability, a neurodevelopmental disorder, is the limitation on the learning abilities of an individual, due to impaired adaptive and intellectual functioning. This disability is one of the several common disabilities in children. The disorder was also known as mental retardation, but the term is not used anymore. The limitation on learning impedes the development of the children, and they tend to learn more slowly than a normal child (Burack, 2012).

The intellectual disability can range from mild to high or severe (Gargiulo \& Bouck, 2017). The only difference among the children with a different range of disability is that bigger the disability, more troublesome it will be to learn and become an independent person. Intellectual disability is identified with the help of IQ test score. The score around 70-75 means the person is having a mild disability (APA, 2018). A score below 70 indicates that moderate intellectual disability is present in the child. The lower the score, more severe will be the condition. The number of children suffering from an intellectual disability is increasing rapidly. It has been found that the prevalence of this disability in America itself is about 36.8 percent (NCBI, 2015).

Intellectual disability basically affects intellectual and adaptive functioning capabilities of a person. The children with intellectual disability face trouble in understanding, speaking, thinking logically, remembering things, and solving problems (APA, 2018; Räty, Kontu \& Pirttimaa, 2016). These children can take a considerable amount of time in learning even the basic everyday-skills such as dressing, bathing, talking, and writing. However, it does not mean that the child with an intellectual disability cannot learn, but there is no known cause of the delay in development in the people who are perceived to suffer from this disability. There are numerous methods and techniques, for instance, UDL that have been developed over the time to enhance the development process and bring these children into the mainstream (Gargiulo and Bouck, 2017).

\section{Universal Design for Extending Learning to Support General Education}

The greatest challenge in today's rapidly changing environment of education is ensuring that no child is left behind, and all of the children have access to general education. However, a wide range of variability in learning exists among students. The students have different interests and strengths, which they try to utilise to learn things. The variation in learning can arise due to several factors including level of intelligence; the level of congruence between teacher; student, and curriculum; background; variation in learning experiences of past; and intellectual disability (Sauce \& Matzel, 2013). Ensuring that all the intellectually disabled children or the students have access to classroom, curriculum, and basic education is difficult because the students have diverse educational needs depending on their ability to learn. Nevertheless, these learners have the ability to attain a high quality of life provided appropriate support is given to them in the classroom (Foreman, 2009).

In order to extend learning to support general education to the students with a variety of differences in learning ability, an innovative approach, universal design for learning can be integrated into the schools. Universal design learning approach is the framework that provides the opportunity to develop a flexible environment, which addresses students' learning variabilities. UDL plays an important role in extending learning to support general education to all students including those with intellectual disability because it helps in making education accessible to all (Katz, 2012). Universal design learning not only assists individuals with intellectual disability but also the students with physical disabilities. The concept of UDL allows the educator to customize the curriculum and the style of teaching according to the needs of the students. It consists of three components (i) multiple means of representation, (ii) multiple means of expression, and (iii) multiple means of engagement (Rao \& Meo, 2016). These components further comprise of modes and ways such as picture, audio, video, and written through which learning can be imparted to the children with intellectual disability. These components help in reducing the barriers to the curriculum without compromising the achievement standards.

UDL allows the teacher to engage students in the learning process regardless of their abilities. For instance, typically in schools, the education is provided in written form and through books. Some students may face the difficulty in reading while some other may experience difficulty in writing. With the help of UDL framework, the students can be educated with multiple means such as pictures, audio, and video. This method provides alternatives to both learner and educator to acquire knowledge and demonstrate information respectively (Hall, Meyer \& Rose, 2012). 
UDL uses Scaffolding approach, which means balancing the child's engagement with the task and modifying it whenever needed. Universal design for learning draws on the strengths and weaknesses of the student and aids in developing the curriculum, which maximizes student's learning (Basham \& Marino, 2013). If considerable support is provided, this technique assists in enabling the disabled child to solve a problem that is beyond his usual unassisted efforts. Using UDL, a teacher can develop a plan preceded by examining the barriers. UDL generally focuses on reducing the barriers so that the teacher does not have to modify lessons to cater to the different needs of intellectually disabled children (Rao \& Meo, 2016; Al-Azawei, Serenelli \& Lundqvist, 2016).

\section{Theories Supporting Access to General Education for Students with Intellectual Disabilities}

In order to meet special educational requirements of students, it is necessary for educational practitioners to evaluate the level to which students require assistance. The need for special education among students can be determined by measuring their intellectual abilities. Special education practitioners require to gain the skills and knowledge needed to measure students' intellectual level for modifying their teaching tactics in accordance with disabilities (Lamport, Graves \& Ward, 2012) Children with autism spectrum disorder, intellectual disabilities, learning disabilities, dyslexia, attention deficit hyperactivity (ADHD) disorder have different teaching needs that can be fulfilled by adopting flexible teaching style. Two kinds of intelligence measures have been proposed under traditional intelligence theory; wherein one measure was based on examining complex cognitive processes and other emphasised on evaluating elementary perceptual processes (Lamport, Graves \& Ward, 2012; Wehmeyer et al., 2003; Wehmeyer, 2006).

It is found out that academic performance of the children and sensory discrimination abilities are positively correlated to each other as children having substantial capability for sensory discrimination exhibit good academic performance (Takahashi, 2013). Hence, an intelligence theory has been developed on the basis of the notion that academic sensory discrimination capability coincides with intelligence. In contrast, it is mentioned that traditional intelligence theory does not have ecological validity due to lack of innovation with respect to cognitive approaches and developmental approaches to intelligence. Traditional intelligence theory has limited applicability as it does not take into consideration differences among social groups and cultural factors (Takahashi, 2013; Lamport, Graves and Ward, 2012). Overall, it has been noted that traditional intelligence theory cannot be used for measuring intellectual abilities students with learning disorders, autism, developmental disorders and other intellectual disorders.

A new approach has been employed for determining learning needs of children with intellectual disabilities, known as the multiple intelligence theory. The theory can be helpful in promoting inclusive education, as well as guiding teachers to obtain adequate competencies and knowledge for helping students with varying needs to access general education curriculum (Takahashi, 2013; Lamport, Graves \& Ward, 2012). The use of multiple intelligence theory contributes in examining eight intelligence areas of children and these results can further be used for employing better teaching approaches in alignment with students' intellectual abilities in special educational settings (Takahashi, 2013; Lamport, Graves \& Ward, 2012). As a whole, it is stated that differentiated instructions is the base of universal design for learning as it ensures that learning needs of intellectually disabled students are properly met.

IDEA asserts that access of curriculum among students with intellectual disabilities can be improved by placing them into adaptable and flexible environment for further increasing their participation in classroom activities amidst students without disabilities (Edyburn, 2010). However, educational institutions and districts struggled to surpass the history of a segregated and a separate education system along with facing challenges in involving students with intellectual disabilities in general education. In this context, inclusion framework is employed within educational settings for supporting access to general education curriculum among intellectually disabled children (Wehmeyer et al., 2003; Wehmeyer, 2006). Various theories support the objectives of IDEA and concept of inclusion such as social learning theory, observation learning theory and guided learning theory. As per social learning theory, behavioural and cognitive learning and development take place via modeling, imitation and observation. The prime characteristics of social learning theory includes observational learnings and components relating to self-efficacy and cognitive contributions (Takahashi, 2013).

Academic modeling and behaviour modeling is possible via verbal instruction and through symbolic modeling in four phases such as retention, attention, motivation and production. Inclusion classes employ these theories for improving the learning among disabled children as they learn by observing non-disabled peers in classrooms (Takahashi, 2013; Lamport, Graves and Ward, 2012). As a whole, amalgamation of Freudian learning principles and social learning theory is helpful in teaching disabled children about social behaviours in real life context. 


\section{Practices followed Universally in Imparting Education to Intellectually Disabled Students}

Inclusive teaching strategies are widely introduced and implemented for fulfilling educational needs of intellectually disabled students universally. Behavioural effectiveness tactics are employed for ensuring that students gain access to general education curriculum. Class wide peer tutoring (CWPT) are regarded to be an effective intervention approach for increasing instructional effectiveness and reducing problem behaviour in classrooms (Howard, 2004). Increased social interaction enables in reducing negative behaviour among intellectually disabled students along with fostering learning among children in educational settings. On the other side, it is discovered that CWPT is more effective in comparison to teacher led instruction as social competence increased among students. However, it is also explored that behavioural disabilities and emotional issues restrict students' ability to interact with peer members that further limit their learning abilities in inclusive educational settings (Coyne et al., 2012).

Curriculum based assessments are also used for reducing negative behaviour of peers and decreasing the tendencies to behaviour inappropriately in classrooms. The study conducted to examine the impact of classroom-based assessment revealed that sound instructional technique results in reducing behavioural problems among students (Lieber et al., 2008). However, including students with intellectual disabilities or behavioural and emotional disorders is a challenging task. In this regard, the effectiveness of intellectually disabled students in general education class can be improved when educators facilitate learning through instructional strategies (Jiménez, Graf \& Rose, 2007). Overall, it has been noted that functional behaviour analysis, teacher made interventions, class wide peer tutoring and curriculum modifications are some of the effective approaches for inclusive teaching, thereby fostering universal design for learning (Jiménez, Graf \& Rose, 2007; Al-Azawei, Serenelli \& Lundqvist, 2016).

Universal design for learning does not only require school professionals and teachers to bring changes in their instructional strategies but effective implementation of UDL for supporting intellectually disabled children requires that educational institutions bring changes on the fundamental level. Universal design for learning via pedagogical tactics and technology illustrate a unifying model that encompasses several approaches for fostering learning through collaboration (Howard, 2004). Educational institutes pay more attention towards changing instructional strategies of tutors for supporting access to general education curriculum to students with intellectual disabilities. There is a need to focus on technology support and infrastructure, providing administrative support, community involvement, teachers training and creative funding for implementing UDL for addressing learning needs of intellectually disabled students in an efficient manner (Edyburn, 2010).

\section{Issues Faced by Intellectually Disabled Students in Accessing General Education}

The students with intellectual disabilities often come across issues in adapting behavioural and functional changes. The intellectual disability creates a negative impact on acquiring new skills, recalling events or things, and generalizing activities, which make it difficult for them to access general education. In addition to this, intellectually disabled students find it difficult to adapt to the changes in conceptual skills, social skills, and practical skills, which slow down and put a limit on their learning abilities. It is common that people, in general, do not readily accept the presence of intellectually disabled children and treat them in a very undesirable manner (Wehmeyer, 2006). Multiple factors affect the access to general education for the intellectually disabled students. The intellectually disabled students have the relatively lower capacity and skills to understand and accept the new things when compared to the students with sound intellectual abilities. In this respect, different methods are used for teaching, enhancing learning, and imparting knowledge to intellectually disabled students (Wehmeyer, 2006; Alnahdi, 2014).

Research results on access to education for intellectually disabled students indicate that there are issues in designing instructions and implementing these instructions in an effective manner. The primary issues concerning with instructional design and implementation relates to the selection of topics to be thought, methods to be adopted for teaching abilities, and selection of teachers for imparting knowledge. The topics and methods to be selected for imparting knowledge to these students need to be very specific based on their individual learning and intellectual capabilities (Coyne et al., 2012). In this respect, selection of appropriate books for reading, functional, language, and arithmetic knowledge is a critical issue among the teachers. In addition to this, teachers often face issues in prioritizing and with designing instructions to enhance day-to-day living skills for these students. The living skills include various skill sets, which include walking style, eating style, hand-writing, personal care, and taking care of personal belongings (Coyne et al., 2012).

Making decisions in concern with whether to provide education to these students in a special setting which are designed keeping in view about their special needs or along with other normal peer students under normal settings is a critical issue for the policy makers and the teachers. Often the intellectually disabled students receive an 
unaccepted treatment from their parents, siblings. peers who are normal, and in social gatherings or at a community level, which reduces their social acceptance resulting in lowering the self-confidence and self-respect of children with special needs (Lee et al., 2009). The pre-set opinions and discriminatory attitude from people in large number act as a major issue by causing the mental blockage for the development and access to basic education for such students. The inferiority behaviour developed in these students owing to unaccepted social behaviour also gets reflected while the students are present in classroom settings (Lee et al., 2009).

In order to get access to general education, it is essential that the students exhibit the capabilities to make decisions and choices that support their development, growth, and overall well-being. However, it is observed that the presence of intellectual disabilities to a great extent hampers the self-determination skills of students affecting their decision-making, time management, choice-making, problem-solving, and goal-setting skills (Jimenez, Graf and Rose, 2007; Kraglund-Gauthier, Young \& Kell, 2014). In this respect, learning new things is a challenging task for students. The legislation that governs the admission and the access to general education for the students with special needs also require to be revised on the priority basis, as the educational institutions are not equipped with the essential tools and facilities that address the special needs of the intellectually disabled children (Jimenez, Graf \& Rose, 2007). The schools do not receive funds in the required amount to meet the needs related with infrastructural, transportation, teaching tools, and the overall environment that ensures comfort and easy access to education for the students with intellectual disabilities. The schools lack the facilities to access knowledge and education through the use of electronic media and information technology, which has become one of the significant modes of communication in the contemporary world (Jimenez, Graf \& Rose, 2007).

\section{Integration of New Universal Design for Enhancing the Learning for Intellectually Disabled Students}

For assimilating universal design learning in the school settings, it is vital to focus on integrating and improving information technology in the schools. For improving this, the teachers must get acquainted with the aspects of IT so that its benefits can be reaped (Wentworth, Earle \& Connell, 2013; Alnahdi, 2014). The teachers must adapt the various techniques through which the students with intellectual disability can be taught. Moreover, proper support from the management must be provided to the teachers and students to use information technology features during the classes and lessons. Apart from this, the educational institutions, where IT is not developed to a significant level, must invest considerable amount of resources in employing technology (Watson \& Tinsley, 2013). Additionally, the teaching models must be changed, and enough focus must be given to equipping each class with technologies for instance televisions and computers so to facilitate the learning process for students with intellectual disability.

The motivation of students with intellectual disabilities is essential in order to ensure healthy living, respectful life, and access to standard living. In this respect, access to quality education can be of great help in their overall development and provide a good quality life to students with intellectual disabilities (Shogren et al., 2012). The integration of new and innovative ways of teaching by following frameworks and principles of universal design for learning can help that teachers to enhance the learning capabilities and knowledge level of the students with intellectual disabilities to a significant extent. Universal design of learning focuses on providing equal opportunities to all the students to participate and access the general education (Shogren et al., 2012).

This enhances the confidence level of the students with intellectual disabilities and enables them to progress at a relatively speedier pace. The integration of the universal design for learning can promote the development of stringent laws that govern the important decision-making processes in concern with the recruitment of teachers, selection of curriculum, and method of teaching (Edyburn, 2010). Further, it can be ensured that the available resources are allocated in an appropriate manner to ensure that priority is given to meet the special needs in concern with infrastructural development and support system of the students with intellectual disabilities (Edyburn, 2010).

It is essential that faulty and unethical practices prevailing in the educational settings in concern with the recruitment of teachers and training processes are discontinued and replaced with better policies. Parents, family members, and society play a significant role in enhancing the acceptance level among the children with intellectual disabilities (Agran et al., 2010; Kraglund-Gauthier, Young \& Kell, 2014). Treating children with love, respect, and care at home and giving them equal social acceptance to access the community belongings and attend social programs expose children to varied settings enabling them to gain new experiences. In this respecting development of a landscape that facilitates communication of the children with other normal peer, parents, teachers, and society can make it easier for the children to access general education. Designing new policy interventions that aim at keeping a check on the integration of healthy practices can help in meeting the changing needs of the students and prepare them for facing the world in a better manner (Agran et al., 2010). 


\section{Conclusion}

The review and analysis of the discussion made above reflect the need for making improvements at the legal, social, and political level for ensuring improved access to general education for students with intellectual disabilities. The students with intellectual learning disabilities have a low level of acceptance for changes in the social or educational environment that reduces their learning capabilities. Therefore, it is required that special arrangements are made to design specific curriculum, integrate infrastructural facilities, new teaching methods, and policies at state and national level that supports the access to general education for students with low mental capabilities. The integration of universal design for learning framework can be of substantial benefit for ensuring that all the students irrespective of their mental health level are given opportunities to access basic education. Access to general education will ensure enhanced learning and development in concern with reading, writing, understanding, decision-making, life skills, and social skills that facilitate the students to live a respectful and standard living. Universal design for learning guides on making changes in the recruitment processes of the teachers and provides training on implementing innovative ways of teaching that can enhance the ability to recall, differentiate, make a choice, and fair evaluation for students with low mental abilities. The training on enhancing behavioural effectiveness and class-wide peer tutoring technique indicates that integration of innovative educational interventions can help in overcoming the issues related to instruction and implementation effectiveness. Therefore, it can be concluded that the teachers must make use of the concept of behaviourism that can help in enhancing the functional and social literacy among the students with intellectual disabilities.

\section{References}

Agran, M., Wehmeyer, M., Cavin, M., \& Palmer, S. (2010). Promoting active engagement in the general education classroom and access to the general education curriculum for students with cognitive disabilities. Education and Training in Autism and Developmental Disabilities, 163-174.

Al-Azawei, A., Serenelli, F., \& Lundqvist, K. (2016). Universal Design for Learning (UDL): A Content Analysis of Peer Reviewed Journals from 2012 to 2015. Journal of the Scholarship of Teaching and Learning, 16(3), 39-56. https://doi.org/10.14434/josotl.v16i3.19295

Alnahdi, G. (2014). Assistive Technology in Special Education and the Universal Design for Learning. Turkish Online Journal of Educational Technology-TOJET, 13(2), 18-23.

APA. (2018). What is Intellectual Disability? Retrieved 09 February 2018 from https://www.psychiatry.org/patients-families/intellectual-disability/what-is-intellectual-disability

Basham, J. D., \& Marino, M.T. (2013). Understanding STEM education and supporting students through universal design for learning. Teaching Exceptional Children, 45(4), 8-15. https://doi.org/10.1177/004005991304500401

Burack, J. A. (2012). The Oxford handbook of intellectual disability and development. Oxford: Oxford Library of Psychology.

Coyne, P., Pisha, B., Dalton, B., Zeph, L. A., \& Smith, N. C. (2012). Literacy by design: A universal design for learning approach for students with significant intellectual disabilities. Remedial and Special Education, 33(3), 162-172. https://doi.org/10.1177/0741932510381651

Edyburn, D. L. (2010). Would you recognize universal design for learning if you saw it? Ten propositions for new directions for the second decade of UDL. Learning Disability Quarterly, 33(1), 33-41. https://doi.org/10.1177/073194871003300103

Foreman, P. (2009). Education of students with an intellectual disability: Research and practice. New York: IAP.

Gargiulo, R. M., \& Bouck, E. C. (2017). Instructional Strategies for Students with Mild, Moderate, and Severe Intellectual Disability. London: SAGE Publications.

Hall, T. E., Meyer, A., \& Rose, D. H. (2012). Universal design for learning in the classroom: Practical applications. NY: Guilford Press.

Howard, K. L. (2004). Universal Design for Learning: Meeting the Needs of All Students. In the Curriculum--Multidisciplinary. Learning \& Leading with Technology, 31(5), 26-29.

Jimenez, T. C., Graf, V. L., \& Rose, E. (2007). Gaining access to general education: The promise of universal design for learning. Issues in Teacher Education, 16(2), 41-54.

Katz, J. (2012). Teaching to diversity: The three-block model of universal design for learning. Winnipeg: Portage \& 
Main Press.

Kraglund-Gauthier, W. L., Young, D. C., \& Kell, E. (2014). Teaching students with disabilities in post-secondary landscapes: Navigating elements of inclusion, differentiation, universal design for learning, and technology. Transformative Dialogues, 7(3), 1-9.

Lamport, M. A., Graves, L., \& Ward, A. (2012). Special needs students in inclusive classrooms: The impact of social interaction on educational outcomes for learners with emotional and behavioral disabilities. European Journal of Business and Social Sciences, 1(5), 54-69.

Lee, S. H., Soukup, J. H., Little, T. D., \& Wehmeyer, M. L. (2009). Student and teacher variables contributing to access to the general education curriculum for students with intellectual and developmental disabilities. The Journal of Special Education, 43(1), 29-44. https://doi.org/10.1177/0022466907313449

Lieber, J., Horn, E., Palmer, S., \& Fleming, K. (2008). Access to the general education curriculum for preschoolers with disabilities: Children's school success. Exceptionality, 16(1), 18-32. https://doi.org/10.1080/09362830701796776

NCBI. (2015). Prevalence of Intellectual Disabilities. Retrieved 09 February 2018 from https://www.ncbi.nlm.nih.gov/books/NBK332894/

Rao, K., \& Meo, G. (2016). Using Universal Design for Learning to Design Standards-Based Lessons. SAGE Open, $6(4), 01-12$.

Räty, L. M., Kontu, E. K., \& Pirttimaa, R. A. (2016). Teaching children with intellectual disabilities: Analysis of research-based recommendations. Journal of Education and Learning, 5(2), 318. https://doi.org/10.5539/jel.v5n2p318

Sauce, B., \& Matzel, L. D. (2013). The causes of variation in learning and behavior: why individual differences matter. Frontiers in psychology, 4, 395-396. https://doi.org/10.3389/fpsyg.2013.00395

Shogren, K. A., Palmer, S. B., Wehmeyer, M. L., Williams-Diehm, K., \& Little, T. D. (2012). Effect of intervention with the Self-Determined Learning Model of Instruction on access and goal attainment. Remedial and Special Education, 33(5), 320-330. https://doi.org/10.1177/0741932511410072

Shurr, J., \& Bouck, E. C. (2013). Research on curriculum for students with moderate and severe intellectual disability: A systematic review. Education and Training in Autism and Developmental Disabilities, 76-87.

Takahashi, J. (2013). Multiple intelligence theory can help promote inclusive education for children with intellectual disabilities and developmental disorders: Historical reviews of intelligence theory, measurement methods, and suggestions for inclusive education. Creative Education, 4(09), 605. https://doi.org/10.4236/ce.2013.49086

Watson, D., \& Tinsley, D. (2013). Integrating information technology into education. London: Springer.

Wehmeyer, M. L., Lattin, D. L., Lapp-Rincker, G., \& Agran, M. (2003). Access to the general curriculum of middle school students with mental retardation: An observational study. Remedial and Special Education, 24(5), 262-272. https://doi.org/10.1177/07419325030240050201

Wehmeyer, M.L. (2006). Universal design for learning, access to the general education curriculum and students with mild mental retardation. Exceptionality, 14(4), 225-235. https://doi.org/10.1207/s15327035ex1404_4

Wentworth, N., Earle, R., \& Connell, M. (2013). Integrating information technology into the teacher education curriculum: process and products of change. London: Routledge. 